\title{
Environmental flow assessment in the Lower Yellow River using habitat simulation and hydrological reference system
}

\author{
Wenxiu Shang ${ }^{1}$, Dengming Yan ${ }^{1 *}$, Shaoming Peng ${ }^{1}$ \\ ${ }^{1}$ Yellow River Engineering Consulting Co., Ltd., Zhengzhou 450003, China
}

\begin{abstract}
The accuracy of the habitat simulation method is often questioned due to limited simulated elements and indicator species. This study established an environmental flow assessment method by coupling fish habitat simulation with hydrological reference system. The environmental flow obtained through the habitat simulation method was corrected by the statistical characteristics of natural flow regime. The environmental flow of the Huayuankou section in the Lower Yellow River was assessed. The results show that the environmental flow demand of the Huayuankou section is $7.9-15.4$ billion $\mathrm{m}^{3} / \mathrm{y}$ without consideration of sediment transport. An environmental baseflow of $220-400 \mathrm{~m}^{3} / \mathrm{s}$ is required throughout the year. One to two high flow pulses are needed in the rising-water season to trigger spawning, followed by flow events of $350-500 \mathrm{~m}^{3} / \mathrm{s}$ with more than 1 week duration to create the spawning grounds.
\end{abstract}

\section{Introduction}

Most of the world's riverine ecosystems are in sharp decline due to increased demand over limited water resources and enhanced river regulation ${ }^{[1-2]}$. River flow is regarded as the main driver involved in maintaining a river's good ecological status [3]. Therefore, environmental flows are increasingly supplied to sustain freshwater and estuarine ecosystems and the human livelihoods and well being that depend upon these ecosystems ${ }^{[4-5]}$.

The habitat simulation methods are based on the hydraulic-habitat preferences of species, offering a direct connection between flow and measurable habitat parameters ${ }^{[6]}$. The advantage of habitat simulation methods is that they take riverine ecosystems into consideration and give an acceptable environmental flow regime rather than fixed minimum environmental flows ${ }^{[7]}$. However, only a few species are chosen as indicator species in habitat simulation, while indicator species often have contrasting habitat requirements to other aquatic biota and little is known of the exact flow requirements to maintain a healthy and robust aquatic community ${ }^{[8-9]}$.

The Yellow River Basin is the second largest basin in China. With the economic development in the Yellow River Basin, the socioeconomic water demand has rapidly increased, which has resulted in insufficient supply of environmental flow ${ }^{[10]}$. In the 1990s, flow cutoffs happened frequently in the Lower Yellow River. In 1997, the flow cutoff lasted for 226 days, and the length of dried up reach was $704 \mathrm{~km}^{[11]}$. The Chinese government has become aware of the ecological problems of the Yellow River. However, the current environmental flow standard

First author's e-mail address: shangwx12@tsinghua.org.cn

Corresponding author's e-mail address: 18519500795@163.com has some drawbacks: firstly, there is no clear correlation between environmental flow and riverine ecosystems; secondly, it mainly focuses on total water volume but does not elaborate on flow process.

This study establishes an environmental flow assessment method that couples fish habitat simulation with hydrological reference system. Taking the Lower Yellow River as an example, the environmental flow in a key section was studied.

\section{Materials and Methods}

\subsection{Basic Compositions of Environmental Flow}

Based on the components of the natural flow regime and their ecological functions ${ }^{[12]}$, the environmental flow designed in this study mainly includes four components: environmental baseflow, high flow pulse, reproductive flow, and flood. The environmental baseflow determines the amount of habitats that can be utilized by aquatic organisms in riverine ecosystems for most of the year. Environmental baseflow is a continuous small river flow throughout the year. High flow pulse events are defined as periods where flow exceeds a certain threshold for a minimum duration ${ }^{[13]}$. Occurring in the rising-water season, high-flow pulses can stimulate the development of aquatic organisms and trigger their migration and reproduction. The function of reproductive flow is to create suitable spawning grounds for aquatic organisms. It is provided during the breeding season of aquatic organisms. Floods include overbank floods and nonoverbank floods. Non-overbank floods can shape river patterns, stabilize habitat patterns, and transport 
sediments. Since there are a large amount of farmland and houses in the floodplain, and water shortage in the Yellow River Basin is severe, this study only considered nonoverbank floods.

\subsection{Fish Habitat Simulation}

Fish are often regarded as effective indicators of riverine ecosystem health since they are at the top of the food chain of riverine ecosystem and often valuable in a social sense [14-15]. The indicator species was selected with consideration of ecological values, endangerment and economic values of native fish species. Afterwards stages of the life cycle of indicator species were identified, and the hydraulic preferences of indicator species in juvenile stage, adult stage and spawning stage were studied.

The simulated area was determined according to habitat distribution, topographic conditions, data acquisition, and distribution of protected areas. A twodimensional hydraulic model was established to simulate the water depth and velocity distribution in the simulated area at different discharges. According to the preferences of indicator species, the distribution of adult fish habitats, juvenile fish habitats, and spawning grounds under different discharges were selected, and the variation of habitat area with discharge were identified.

According to the simulation results, the peak value of adult fish habitat area $\left(H_{1, \max }\right)$, the peak value of juvenile habitat area $\left(H_{2, \max }\right)$, and the peak value of spawning grounds $\left(H_{3, \max }\right)$ were identified. This study assumed that when the habitat area was no less than $1 / 3$ of the peak value, it was suitable for indicator species to inhabit. According to the habitat area-discharge curve, the discharge ranges suitable for adult fish $\left(A_{\min }-A_{\max }\right)$, juvenile fish $\left(J_{\min }-J_{\max }\right)$, and spawning $\left(S_{\min }-S_{\max }\right)$ were determined.

\subsection{Hydrological Reference System}

Native species have adapted to local natural flow regime during long-term evolution. The assumption that the natural flow regime is the most suitable to native species is well supported by substantial data and observations ${ }^{[16]}$. Therefore, this study assumed that natural flow regime could reflect the tolerance of native species to flow conditions. The natural flow regime was used as a reference system to correct the environmental flow produced from fish habitat simulation.

The minimum flow that occurs naturally is the worst hydrological condition that all native aquatic organisms have experienced and successfully survived. Therefore, the minimum natural flow $\left(N_{\min }\right)$ was counted as the lower flow limit that all native aquatic organisms could tolerate.

The high flow pulses under natural conditions have successfully triggered reproduction. Thus the characteristics of high flow pulses under natural conditions were used to design high flow pulses in the environmental flow. The number of high flow pulses that could be guaranteed in $80 \%$ of the years under natural conditions was counted as the number of high flow pulses required for environmental flow $(N)$. The occurrence time of high flow pulses under natural conditions was analyzed, and the main time when high flow pulses occurred was regarded as the suitable occurrence time of high flow pulses of environmental flow $\left(P_{t, 1}, P_{t, 2}, \ldots P_{t, N}\right)$. The duration, peak flow, flow rising rate (positive differences between consecutive daily mean flows), and flow falling rate (negative differences between consecutive daily mean flows) of high flow pulses under natural conditions was calculated. The interval from $1 / 3$ quantile to $2 / 3$ quantile was used as the appropriate range of the duration $\left(P_{d}\right)$, the peak flow $\left(P_{\max }\right)$, the flow rising rate $\left(P_{\text {rate }, r i}\right)$, and the flow falling rate $\left(P_{\text {rate } f a}\right)$ of high flow pulses of environmental flow. The average flow of high flow pulses under natural conditions was regarded as the appropriate average flow $\left(P_{\text {mean }}\right)$ of high flow pulses of environmental flow.

Low flow events that last for days to weeks often occurred after high flow pulses. The low flow events could create slow flow and provide suitable spawning grounds for fish that produce adhensive eggs. The flow variation range $\left(N_{s, \min }-N_{s, \max }\right)$ of the low flow events under natural conditions was calculated.

\subsection{Coupling of Environmental Flow Assessment Methods}

Taking the fish habitat simulation as the core and the natural flow regime as the reference, the two methods can complement and correct each other.

The environmental baseflow needs to be provided throughout the year, mainly considering three factors: the adult fish habitat, the juvenile fish habitat, and natural flow regime. The overlapping of the flow range suitable for adult fish, the flow range suitable for juvenile fish, and the natural flow variation range was taken as the variation range of the environmental baseflow $\left(E_{b, \min }-E_{b, \max }\right)$, as shown in equations (1) and (2).

$$
\begin{aligned}
& E_{b, \min }=\max \left(A_{\min }, \quad J_{\min }, \quad N_{\min }\right) \\
& E_{b, \max }=\min \left(A_{\max }, \quad J_{\max }\right)
\end{aligned}
$$

The high flow pulse assessed on the basis of the hydrological reference system was employed.

The overlapping of the flow range suitable for the spawning of the indicator species and the natural flow variation of low flow events in the rising-water season was taken as the variation range of the reproductive flow (Es,min-Es,max), as shown in equations (3) and (4).

$$
\begin{aligned}
& E_{s, \text { min }}=\max \left(S_{\text {min }}, \quad N_{s, \text { min }}\right) \\
& E_{s, \max }=\min \left(S_{\max }, \quad N_{s, \max }\right)
\end{aligned}
$$

In order to maintain the safety of life and property in the floodplain, only non-overbank floods were considered in this study. Based on the habit area-flow curve, the high flow range that was appropriate for the adult fish and juvenile fish to inhabit was selected. 


\section{Case study}

\subsection{Study Area}

The study area was the Lower Yellow River (Figure 1). The Lower Reach of the Yellow River is $786 \mathrm{~km}$. With high sediment concentration and frequent swings of river channels, zonal distributed floodplain wetlands have been formed and provided habitats for a variety of organisms. The Lower Yellow River has been disturbed by human activities seriously and the ecological damage is severe in this region.

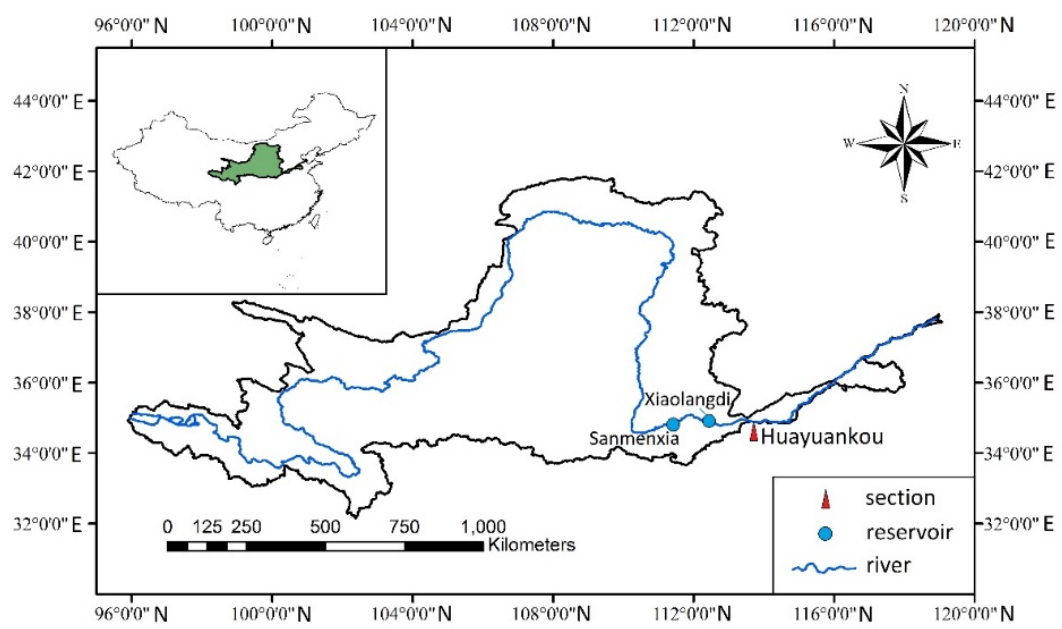

Figure 1. The Yellow River Basin and the study area.

\subsection{Habitat Simulation Model Construction and Calibration}

Carp (Cyprinus carpio) was selected as the indicator species for environmental flow assessment in the Lower Yellow River. The hydraulic preferences of carp at different life stages are shown in Table $1^{[17]}$.

Table 1. Hydraulic preferences of carp at different life stages in the Lower Yellow River.

\begin{tabular}{cccc}
\hline & \multicolumn{3}{c}{ Habitat type } \\
\cline { 2 - 4 } $\begin{array}{c}\text { Hydraulic } \\
\text { condition }\end{array}$ & $\begin{array}{c}\text { Adult } \\
\text { fish } \\
\text { habitat }\end{array}$ & $\begin{array}{c}\text { Juvenile } \\
\text { habitat }\end{array}$ & $\begin{array}{c}\text { Spawning } \\
\text { ground }\end{array}$ \\
\hline Water depth $/ \mathrm{m}$ & $>1.5$ & $>1$ & $1-2$ \\
Velocity $/(\mathrm{m} / \mathrm{s})$ & $0.1-0.8$ & $<0.3$ & $0.1-0.6$ \\
\hline
\end{tabular}

This study chose the Huayuankou section as an example to assess the environmental flow in the Lower Yellow River. A 20-km river reach around the Huayuankou section was chosen as the simulated area. The simulated area was approximately $20,000 \mathrm{ha}$, including the main channel and the floodplain. A two-dimensional hydraulic model was established using MIKE21, and was calibrated by the measured flow-depth relationship in the Huayuankou section. The simulation results of the hydraulic model were input into ArcGIS, and the grids with suitable water depth and velocity were selected to generate the distribution and area of carp habitat.

\subsection{Hydrological Reference System Selection}

The Sanmenxia Reservoir is located in the upstream of Huayuankou. This reservoir is the earliest reservoir on the mainstream of the Yellow River whose construction started in April 1957. Before 1957, the Yellow River Basin had a small population and low productivity. There was no reservoir in the mainstream. The water withdrawal was small. Therefore, the measured runoff before 1957 could be regarded as natural runoff. Hence the measured flow regime before 1957 was used as the hydrological reference system.

\section{Results and discussion}

\subsection{Habitat Distribution of Indicator Species}

The simulation results of carp habitat under different discharges are shown in Figures 2. For adult fish, habitats were located throughout the main channel when the discharge was small. As the discharge increased, the habitat area rapidly increased, reaching a peak at 400-600 $\mathrm{m}^{3} / \mathrm{s}$. The habitat area then decreased with increasing discharge, and the distribution of habitat gradually transferred to the edge of the water. The adult fish habitat area stabilized at a low level at $3000-7000 \mathrm{~m}^{3} / \mathrm{s}$. Overbank flood happened at $7500 \mathrm{~m}^{3} / \mathrm{s}$, but the water was shallow and did not form suitable habitat in the floodplain. When the discharge reached $8000 \mathrm{~m}^{3} / \mathrm{s}$, adult fish habitat appeared in the floodplain. Then the habitat area rapidly increased with increasing discharge. 


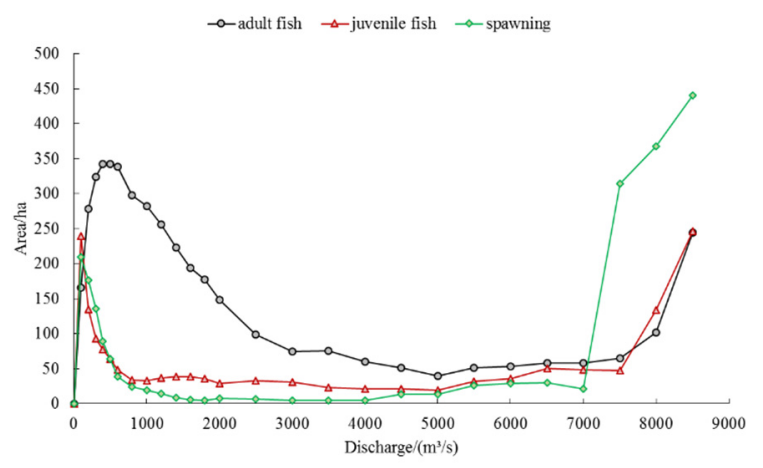

Figure 2. Relationship between the carp habitat area and discharge in the simulated area. The bankfull discharge in the simulated area is $7200 \mathrm{~m}^{3} / \mathrm{s}$.

For juveniles, the habitat area was large at small discharges, and was mainly distributed at the edge of the adult fish habitat. Then the habitat area rapidly decreased as the discharge increased. At $800-7000 \mathrm{~m}^{3} / \mathrm{s}$, the habitat area stabilized at a low level. When the discharge were more than $8000 \mathrm{~m}^{3} / \mathrm{s}$, the habitat area of juvenile fish began increasing rapidly with the increase of discharge.

A large area of spawning grounds was formed in the simulated are at low discharge. Then the area of the spawning grounds decreased rapidly as the discharge increased. At $800-7000 \mathrm{~m}^{3} / \mathrm{s}$, the spawning area stabilized at a low level. There was almost no suitable spawning ground at $1400-4000 \mathrm{~m}^{3} / \mathrm{s}$. When overbank flood happened, slow-flowing water area was formed quickly in the floodplain, resulting in significantly increase of spawning grounds.

According to the habitat area-discharge curve of carp in the simulated area, it was obtained that the flow range suitable for adult carp $\left(A_{\min }-A_{\max }\right)$ was $100-2300 \mathrm{~m}^{3} / \mathrm{s}$; the flow range suitable for juvenile carp $\left(J_{\min }-J_{\max }\right)$ was 100 $400 \mathrm{~m}^{3} / \mathrm{s}$; and the flow range suitable for the spawning of carp $\left(S_{\min }-S_{\max }\right)$ was $100-500 \mathrm{~m}^{3} / \mathrm{s}$.

\subsection{Statistical Characteristics of Hydrological Reference System}

The analysis of the measured daily runoff of the Huayuankou section before 1957 showed that the minimum daily runoff flow $N_{\min }$ was $220 \mathrm{~m}^{3} / \mathrm{s}$.

According to the flow characteristics of the Huayuankou section during the rising-water season, a flow event with a discharge exceeding $1000 \mathrm{~m}^{3} / \mathrm{s}$ and a duration exceeding 3 days was regarded as a high flow pulse event. Since high flow events happen frequently in middle and late June as the flood season (July-October) is coming, and the time for spawning and hatching needs to be reserved, so only high flow pulses that occurred from April 1 to June 10 were counted.

The results showed that high flow pulses occurred 0 to 4 times a year, with an average of 2 times. The first high flow pulse generally occurred in early April, and the second high flow pulse generally occurred in early May. The high flow pulse duration was 5-35 days, and 80\% high flow pulses' duration were no more than 20 days. The peak flow was $1120-2800 \mathrm{~m}^{3} / \mathrm{s}$. The average flow was $1200 \mathrm{~m}^{3} / \mathrm{s}$. The flow rising rate was greater than the flow falling rate. The $1 / 3$ quantile and the $2 / 3$ quantile of high flow pulse duration, peak flow, flow rising rate, and flow falling rate are shown in Table 2 .

The low flow event that occurs after a high flow pulse during the rising-water season can create spawning grounds for a variety of fish that produce adhensive eggs. The duration of the low-flow event was set as 7 days, taking into account the time required for fish spawning, egg hatching, and early development of juveniles in the Lower Yellow River. The characteristics of low flow events in the Huayuankou section before 1957 were analyzed. The results showed that the flow variation range of low flow events $\left(N_{s, \min }-N_{s, \max }\right)$ was $350-980 \mathrm{~m}^{3} / \mathrm{s}$.

Table 2. Main parameters of high flow pulses required in the environmental flow of the Huayuankou section in the Lower Yellow River.

\begin{tabular}{ccc}
\hline Key parameters & $\begin{array}{c}\text { Variable } \\
\text { symbol }\end{array}$ & Value \\
\hline $\begin{array}{c}\text { Number of high flow } \\
\text { pulses per year }\end{array}$ & $N$ & $1-2$ \\
& $P_{t, 1}$ & Early April \\
Occurrence time & $P_{t, 2}$ & Early May \\
& $P_{d}$ & $10-20 \mathrm{~d}$ \\
Duration & $P_{\text {max }}$ & $1500-2000$ \\
Peak flow & $P_{\text {rate, } r i}$ & $60-200$ \\
Flow rising rate & $\mathrm{m}^{3} /(\mathrm{s} \cdot \mathrm{d})$ \\
Flow falling rate & $P_{\text {rate }, f a}$ & $60-150$ \\
& $\mathrm{~m}^{3} /(\mathrm{s} \cdot \mathrm{d})$ \\
Average flow & $P_{\text {mean }}$ & $1200 \mathrm{~m}^{3} / \mathrm{s}$ \\
\hline
\end{tabular}

\subsection{Environmental Flow in the Lower Yellow River}

According to equations (1) and (2), the environmental baseflow of the Huayuankou section is $220-400 \mathrm{~m}^{3} / \mathrm{s}$. When the environmental baseflow is small, it is more suitable for juveniles to inhabit. When the environmental baseflow is large, it is more suitable for the growth and development of adult carp. The high flow pulse is determined by the statistical characteristics of the hydrological reference system, as shown in Table 2.

According to equations (3) and (4), the reproductive flow varied from 350 to $500 \mathrm{~m}^{3} / \mathrm{s}$. The hatching of carp eggs takes 2-3 days, and the juvenile fish needs 2-4 days to leave the spawning ground, therefore, the reproductive flow duration needs to be no less than $7 \mathrm{~d}$. The habitat area of adult carp and juvenile carp remained basically stable during non-overbank floods. The Yellow River has lots of sediment. Thus sediment transport is an important purpose of environmental flow. Therefore, the timing and magnitude of floods in the Huayuankou section mainly depends on the demand of sediment transport, which is not explicitly mentioned in this study. Without consideration of the sediment transport, the environmental flow of the Huayuankou section is 7.9-15.4 billion $\mathrm{m}^{3} / \mathrm{y}$. The environmental flow assessed in this study is dissimilar to the natural flow regime. However, 
offering high flow pulses at suitable time and releasing stable baseflow at other time is regarded as a costeffective management strategy ${ }^{[18]}$.

\section{Conclusions}

In this study, fish habitat simulation was used as the main environmental flow assessment method, while the natural flow regime was used as the reference system. The environmental flow of the Huayuankou section in the Lower Yellow River was assessed. Without consideration of floods for sediment transport, the annual environmental flow required in the Huayuankou section is 7.9-15.4 billion $\mathrm{m}^{3}$, and it is necessary to provide 1-2 high flow pulses in the rising-water season and to create flow events that generate suitable spawning grounds.

The habitat simulation model established in this study only considered the influence of flow velocity and water depth on the indicator species, whereas important factors such as water temperature and dissolved oxygen were not included. The improvement of the habitat simulation model is the future research directions of this study.

\section{Acknowledgments}

This paper was supported by National Natural Science Foundation of China (Grant No. 51879240).

\section{References}

1. Poff, N.L., Richter, B.D., Arthington, A.H., et al. The ecological limits of hydrologic alteration (ELOHA): a new framework for developing regional environmental flow standards. Freshwater Biol. 2010, 55, 147-170.

2. Ocock, J.F., Bino, G., Wassens, S., et al. Identifying critical habitat for Australian freshwater turtles in a large regulated floodplain: implications for environmental water management. Environ. Manage. 2018, 61, 375-389.

3. Pastor, A.V.;, Ludwig, F., Biemans, H., et al. Accounting for environmental flow requirements in global water assessments. Hydrol. Earth Syst. Sci. 2014, 18, 5041-5059.

4. Davies, P.M., Naiman, R.J., Warfe, D.M., et al. Flow-ecology relationships: closing the loop on effective environmental flows. Mar. Freshwater Res. 2014, 65, 133.

5. Mackie, J.K., Chester, E.T., Matthews, T.G., et al. Macroinvertebrate response to environmental flows in headwater streams in western Victoria, Australia. Ecol. Eng. 2013, 53, 100-105.

6. Gates, K.K., Vaughn, C.C., Julian, J.P. Developing environmental flow recommendations for freshwater mussels using the biological traits of species guilds. Freshwater Biol. 2015, 60, 620-635.

7. Nikghalb, S., Shokoohi, A., Singh, V.P., et al. Ecological regime versus minimum environmental flow: comparison of results for a river in a Semi Mediterranean Region. Water resour. Manag. 2016, 30, 4969-4984.

8. Theodoropoulos, C., Skoulikidis, N., Rutschmann, P., et al. Ecosystem-based environmental flow assessment in a Greek regulated river with the use of $2 \mathrm{D}$ hydrodynamic habitat modelling. River Res. Appl. 2018, 34, 538-547.

9. Bunn, S.E., Arthington, A.H. Basic Principles and Ecological Consequences of Altered Flow Regimes for Aquatic Biodiversity. Environ. Manage. 2002, 30, 492-507.

10. Zhang, Q., Singh, V.P., Li, J. Eco-hydrological requirements in arid and semiarid regions: Case study of the Yellow River in China. J. Hydrol. Eng. 2012, 18, 689-697.

11. Kong, D., Miao, C., Borthwick, A.G., et al. Evolution of the Yellow River Delta and its relationship with runoff and sediment load from 1983 to 2011. J. Hydrol. 2015, 520, 157-167.

12. Poff, N.L., Allan, J.D., Bain, M.B., et al. The natural flow regime: a paradigm for river conservation and restoration. Bioscience 1997, 47, 769-784.

13. Horne, A., Kaur, S., Szemis, J., et al. Using optimization to develop a "designer" environmental flow regime. Environ. Modell. Softw. 2017, 88, 188199.

14. Viliam, M., Zuzana, Š., Martina, M., et al. Influence of discharge on fish habitat suitability curves in mountain watercourses in IFIM methodology. $J$. Hydrol. Hydromech. 2018, 66, 12-22.

15. Wang, P., Shen, Y., Wang, C., et al. An improved habitat model to evaluate the impact of water conservancy projects on Chinese sturgeon (Acipenser sinensis) spawning sites in the Yangtze River, China. Ecol. Eng. 2017, 104, 165-176.

16. Poff, N.L., Allan, J.D. Functional organization of stream fish assemblages in relation to hydrological variability. Ecology 1995, 76, 606-627.

17. Jiang, X., He, H., Qv, S., et al. Condition of the aquatic ecosystem of the mainstream of the Yellow River. In Impacts of Reservoirs in the Mainstream of the Yellow River on Riverine Ecosystem and Ecological Regulation, 1st ed.; Jiang, X.; He, H., Eds. Yellow River Water Conservancy Press: Zhengzhou, China, 2012; pp. 24-61.

18. Poff, N.L., Schmidt, J.C. How dams can go with the flow. Science 2016, 353, 1099-1100. 